\title{
STRES KERJA, KEPUASAN KERJA, DAN IKLIM ORGANISASI TERHADAP TURNOVER INTENTION PADA DIVISI KEUANGAN PT XYZ
}

\author{
GENUINE EKA PRASETIYO \\ SETIA TJAHYANTI \\ Trisakti School of Management, Jl. Kyai Tapa No. 20 Jakarta 11440, Indonesia \\ genuineeka@gmail.com
}

\begin{abstract}
The purpose of this research is to examine the effect of human resource management practice such as work stres, job satisfaction and organization climate on turnover intention of Finance Division PT. Mayora Indah Tbk Head Office Jakarta. The sampling in this research was purposive sampling, in which only 89 collected data that accordance with the criteria. Data for this study comes from primary source garnered by distributing LikertScale questionnaires. The data is then analyzed with SPSS version 23 program using Simple Linear Regressions and Multiple Regressions Analysis. The result on this research is work stres and organization climate have a significant influence to turnover intention individually. Job satisfaction not have a significant influence to turnover intention.
\end{abstract}

Keywords: Work stress; job satisfaction; organizational climate; turnover intention.

Abstrak: Tujuan penelitian adalah untuk menganalisa pengaruh praktek manajemen sumber daya manusia seperti Stres Kerja, Kepuasan Kerja, dan Iklim Organisasi terhadap turnover intention pada Divisi Keuangan PT Mayora Indah Tbk Kantor Pusat Jakarta. Sampel didapat melalui metode purposive sampling, dimana yang sesuai dengan kriteria berjumlah 89 data. Data yang didapat berasal dari data primer yang di kumpulkan melalui kuesioner dengan skala likert. Data dianalisis dengan program SPSS (Statistical Package for Social Science) versi 23 dengan menggunakan Regresi Sederhana dan Regresi Linier Berganda. Hasil dari penelitian ini adalah stress kerja dan iklim organisasi berpengaruh signifikan terhadap turnover intention secara individual. Kepuasan kerja tidak berpengaruh signnifikan terhadap turnover intention.

Kata kunci: Stres kerja, kepuasan kerja, iklim organisasi, turnover intention

\section{PENDAHULUAN}

Kebutuhan akan tenaga kerja cenderung terus bertambah seiring pemenuhan pencapaian perusahaan. Berdasarkan survey lembaga BPS, terdapat 5 sektor utama yang mampu menyerap tenaga kerja secara masal yaitu, sektor pertanian, industri, jasa akomodasi, jasa kemasyarakatan, dan properti. Pada tahun 2011 hingga 2015 tercatat, industri yang mampu menyerap tenaga kerja terbesar yaitu pada sektor industry makanan.

Menurut Haris Munandar (Sekretaris Jendral Kementrian Perindustrian) Sektor makanan dan minuman mendominasi penyerapan tenaga kerja di bidang industri, yakni sebanyak 3.3 juta orang atau sebesar 21,34 \% dari 16,6 juta tenaga kerja dibidang industri. 


\section{Tabel 1 Jumlah Tenaga Kerja Industri Besar dan Sedang Menurut Sub Sektor Makanan dan Minuman}

\begin{tabular}{llllll}
\hline Sub Sektor & 2011 & 2012 & 2013 & 2014 & 2015 \\
\hline $\begin{array}{l}\text { Makanan \& } \\
\text { Minuman }\end{array}$ & 785.462 & 931.293 & 953.178 & 930.472 & 918.143 \\
Sumber: www.bps.go.id & & & & \\
\hline
\end{tabular}

Penyerapan tenaga kerja pada industri makanan dan minuman di Indonesia mengalami peningkatan dari tahun 2011 hingga 2013 namun memiliki penurunan pada tahun 2014 dan 2015 hal tersebut sebanding dengan pertumbuhan FMCG di Indonesia. Fast Moving Consumer Goods adalah salah satu kategori industry di bidang makanan dan minuman. Fast Moving Consumer Goods (FMCG) adalah produk yang memiliki perputaran omset dengan cepat, dan biaya yang relatif rendah. Produk FMCG memiliki masa simpan yang relatif singkat karena sifatnya yang cepat rusak. Kategori produk FMCG umumnya mencakup berbagai macam produk konsumen yang sering dibeli termasuk peralatan mandi, sabun, kosmetik, pasta gigi, pisau cukur dan deterjen, serta non-durable seperti gelas, lampu, baterai, produk berbahan kertas dan barangbarang plastik.

Berdasarkan survey Nielsen, FMCG selama 2017 tercatat hanya tumbuh 2,7 persen. Sementara 2016 lalu pertumbuhan FMCG mampu mencapai 7,7 persen. Berdasarkan pengamatan, tercatat rata rata pertumbuhan normal FMCG mencapai 11 persen. Terdapat sejumlah faktor yang membuat pertumbuhan FMCG tahun ini hanya tumbuh 2,7 persen. Diantaranya, pengurangan konsumsi di kelas menengah ke bawah sebagai porsi yang besar terjadi karena menurunnya takehome pay (THP/gaji total) dan kenaikan harga utility.

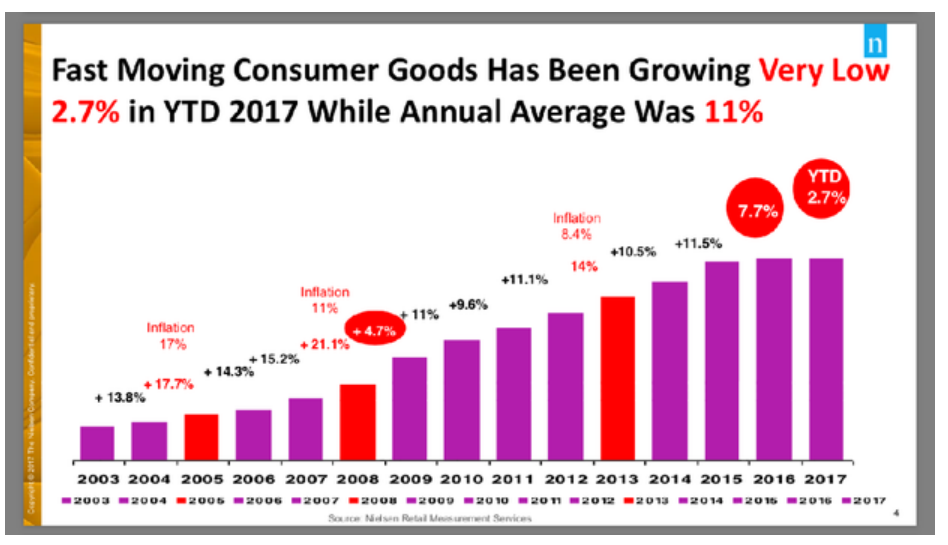

Gambar 1 Pertumbuhan Industri Fast Moving Customer Goods

PT. Mayora Indah Tbk adalah (Perseroan) yang didirikan pada tahun 1977 yang bergerak dalam industry makanan dan minuman yang memproduksi dan memiliki 6 divisi yang menghasilkan produk berbeda. Selama beberapa dekade, Mayora Group tumbuh menjadi salah satu nama yang diakui di industri Fast-Moving Consumer Goods (FMCG). Kemampuannya mengidentifikasi kebutuhan 
pasar dan komitmen untuk menghasilkan

produk berkualitas telah dikenal dunia

Tabel 2 Tingkat Turnover Industry Perseroan Terbatas

\begin{tabular}{ll}
\hline Industri & Tingkat Turnover (\%) \\
\hline Perbankan & $16 \%$ \\
Other durable goods manufacturing & $13 \%$ \\
Kesehatan & $11 \%$ \\
Other non-manufacturing & $11 \%$ \\
Pertambangan \& Logam & $7 \%$ \\
Other non-durable goods manufacturing & $6 \%$ \\
Energy & $5 \%$ \\
Retail and Wholesale & $2 \%$ \\
Asuransi & $1 \%$ \\
\hline
\end{tabular}

Sumber: www.swa.co.id

Berdasarkan survei SWA terhadap turnover karyawan industri manufactur barang yang tidak tahan lama atau yang termasuk kategori FMCG di Indonesia berada di angka 6\%, sedangkan untuk tingkat turnover karyawan di PT. Mayora Indah Tbk berada dibawah rata rata Turnover Karyawan pada Industri sejenisnya

Permasalahan tingginya tingkat turnover intention telah menjadi masalah serius bagi banyak perusahaan. Dampak negatif yang dirasakan akibat terjadinya turnover intention pada perusahaan yaitu pada kualitas dan kemampuan perusahaan untuk menggantikan karyawan yang keluar dari perusahaan, sehingga butuh waktu serta biaya dalam merekrut karyawan baru (Supayah, 2010).

Maka bila dilihat dari sisi kinerja dari perusahaan, perusahaan mampu mengelola para pekerjanya sebaik mungkin karena mampu memberikan pelayanan yang memuaskan bagi para konsumen konsumennya. Dengan melihat dari kepuasan kerja yang dimiliki oleh para pekerjanya.

Penelitian ini merupakan replikasi penelitian dari I Gede Putra Arnanta dan I Wayan Mudiartha Utama (2015) yang berjudul "Pengaruh Sress Kerja, Kepuasan Kerja dan Iklim Organisasi terhadap Turnover Intention" adapun perbedaan yang dilakukan pada penelitian ini terletak pada objek penelitian. Pada penelitian sebelumnya menggunakan karyawan CV. Dharma Siadja, sedangkan pada penelitian ini menggunakan PT Mayora Indah Tbk Kantor Pusat Jakarta sebagai objek penelitian,

Berdasarkan latar belakang diatas, maka dapat diambil rumusan masalah dari penelitian ini sebagai berikut:

1. Apakah terdapat pengaruh Stres Kerja terhadap Turnover Intention pada Divisi Keuangan PT. Mayora Indah Tbk Kantor Pusat Jakarta?

2. Apakah terdapat pengaruh Kepuasan Kerja terhadap Turnover Intention pada Divisi Keuangan PT. Mayora Indah Tbk Kantor Pusat Jakarta?

3. Apakah terdapat pengaaruh Iklim Organisasi terhadap Turnover Intention pada Divisi Keuangan PT. Mayora Indah Tbk Kantor Pusat Jakarta?

\section{Stres Kerja}

Robbins (2003) mendefinisikan stress kerja sebagai kondisi dimana individu menghadapi peluang, kendala, atau tuntutan yang berhubungan dengan apa yang diinginkan dan hasilnya dianggap tidak pasti tetapi penting. Stres kerja adalah suatu kondisi karyawan yang mengalami tekanan dalam pekerjaan baik dari tugas, pimpinan dan lingkungan kerja tempat karyawan tersebut bekerja. Menurut Handoko 
(2008:200) stres kerja adalah suatu kondisi ketegangan yang mempengaruhi proses berpikir, emosi, dan kondisi seseorang, hasilnya stres yang terlalu berlebihan dapat mengancam kemampuan seseorang untuk menghadapi lingkungan dan pada akhirnya akan mengganggu pelaksanaan tugas tugasnya

\section{Kepuasan Kerja}

Menurut Sutrisno (2012), kepuasan kerja adalah perasaan senang atau bahagia seorang pekerja dalam menghormati dan melaksanakan pekerjaannya. Kepuasan kerja dalam menjalankan fungsinya tidak berdiri sendiri, tetapi berhubungan dengan kinerja dan tingkat imbalan, dipengaruhi oleh ketrampilan, kempuan dan sifat-sifat individu. Robbins (2008) menyatakan kepuasan kerja mendorong munculnya OCB karena karyawan yang puas memiliki kemungkinan yang lebih besar untuk berbicara positif tentang organisasi membantu individu lain, dan melakukan kinerja yang melampaui perkiraan normal.

\section{Iklim Organisasi}

Sukarman (2012) Iklim organisasi adalah hubungan antar individu yang dapat mempengaruhi perilakunya sehingga dapat meningkatkan produktivitas kerja. Harris (2009) Iklim organisasi adalah seperangkat karakteristik yang mendefinisikan sebuah organisasi dan membedakan organisasi tertentu dengan organisasi lain. Dessler (2017) Iklim Organisasi adalah persepsi karyawan perusahaan berbagi tentang lingkungan fisik perusahaan, misalnya dalam hal hal-hal seperti kepedulian terhadap kesejahteraan karyawan, perilaku pengawasan, fleksibilitas, apresiasi, etika, pemberdayaan, perilaku politik, dan kebalikannya

\section{Turnover Intention}

Robbins (2008) penarikan diri seseorang keluar dari suatu organisasi (turnover) dapat diputuskan secara sukarela (voluntary turnover) maupun secara tidak sukarela (involuntary turnover). Turnover intention adalah keinginan untuk berpindah, belum sampai pada tahap realisasi yaitu melakukan perpindahan dari satu tempat kerja ke tempat kerja lainnya. Turnover intention merupakan suatu fenomena dimana karyawan memliki keinginan atau niat untuk mencari alternatif pekerjaan di perusahaan lain (Panggabean 2004). Kerangka pemikiran penelitian ini dapat digambarkan sebagai berikut:

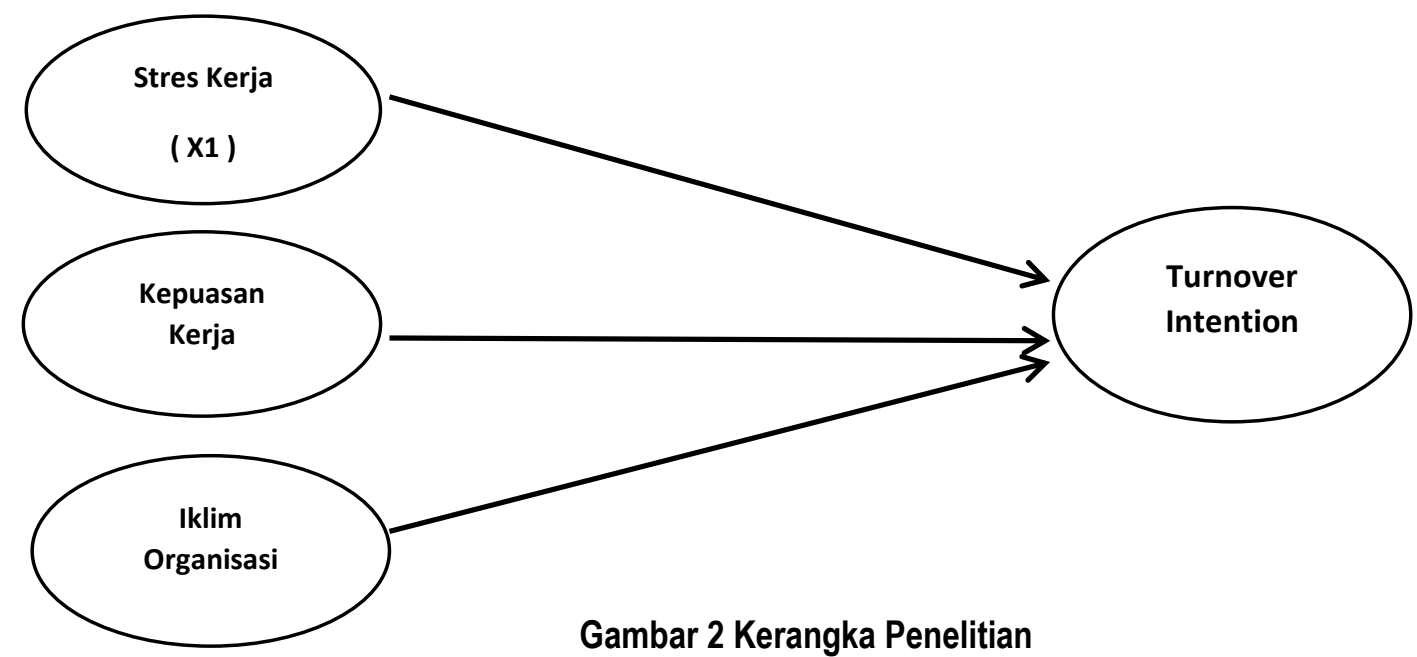


$\mathrm{H}_{1}$ Terdapat pengaruh Stres Kerja terhadap Turnover Intention.

$\mathrm{H}_{2}$ Terdapat pengaruh Kepuasan Kerja terhadap Turnover Intention.

$\mathrm{H}_{3}$ Terdapat pengaruh Iklim Organisasi terhadap Turnover Intention.

\section{METODE PENELITIAN}

Bentuk penelitian yang akan dilakukan dalam penelitian ini adalah bentuk hubungan kausal, yaitu hubungan yang bersifat sebab akibat yang didalamnya terdapat variable independen atau variabel yang mempengaruhi dan variabel dependen atau variable yang dipengaruhi (Sugiyono 2016, 37). Menurut Sugiyono (2016) populasi adalah wilayah generalisasi yang terdiri atas obyek atau subyek yang mempunyai kualitas dan karakteristik tertentu yang ditetapkan oleh peneliti untuk dipelajari dan kemudian ditarik kesimpulannya. Populasi yang diambil dalam penelitian ini adalah seluruh staf di Divisi Keuangan PT. Mayora Indah Tbk Kantor Pusat Jakarta sebanyak 97 staf. Sedangkan sampel adalah bagian dari jumlah dan karakteristik yang dimiliki oleh populasi tersebut (Sugiyono 2016). Jumlah kuesioner yang disebar sebanyak 95 kuesioner. Teknik pengambilan sampel yang digunakan adalah purposive sampling yaitu teknik penentuan sampel dengan pertimbangan tertentu (Sugiyono 2016, 81). Kriteria responden adalah yang sudah bekerja minimal 1 tahun, umur lebih dari 20 tahun pada Divisi Keuangan PT. Mayora Indah Tbk Kantor Pusat Jakarta.
Adapun kuesioner yang kembali sebanyak 91 kuesioner. Dan kuesioner yang dipergunakan dalam penelitian sebanyak 89 kuesioner Stres kerja adalah kondisi ketegangan yang menciptakan adanya ketidakseimbangan fisik dan psikis yang mempengaruhi emosi. Kepuasan kerja adalah suatu perasaan positif atau emosi positif yang merupakan hasil persepsi pengalaman selama masa kerjanya. Iklim organisasi adalah seperangkat karakteristik yang mendefinisikan sebuah organisasi dan membedakan organisasi tertentu dengan organisasi lain. Iklim organisasi yang baik harus dimiliki setiap perusahaan dan harus dibudayakan di kalangan karyawan agar dapat mendukung tercapainya tujuan organisasi karena merupakan wujud dari kepatuhan terhadap aturan kerja. Turnover intention adalah niat seseorang untuk meninggalkan perusahaan atau organisasi dan berkeinginan pindah ke perusahaan lain.

Skala yang digunakan dalam pengukuran ini adalah skala Likert. Menurut Sugiyono $(2016,93)$ skala Likert adalah skala yang digunakan untuk mengukur sikap, pendapat, dan persepsi seseorang atau sekelompok orang tentang fenomena sosial. Dengan menggunakan skala likert, maka variabel yang akan diukur dijabarkan menjadi beberapa indikator. Kemudian indikatorindikator yang terukur ini dijadikan titik tolak untuk membuat item instrumen yang berupa pertanyaan-pertanyaan atau pernyataan yang perlu dijawab responden 
Tabel 3 Indikator Variabel

\begin{tabular}{ll}
\hline Stres Kerja (X1) & 1. Peran dalam Organisasi \\
& 2. Konflik Peran \\
& 3. Beban Kerja \\
& 4. Hubungan Kerja \\
& 5. Iklim Organisasi \\
Kepuasan Kerja (X2) & 1. Kesesuaian Pekerjaan \\
& 2. Pekerjaan itu sendiri \\
& 3. Upah dan Promosi \\
& 4. Rekan Sekerja \\
& 5. Atasan \\
& 6. Lingkungan Kerja \\
1. Kesesuaian dengan Organisasi \\
Iklim Organisasi (X3) & 2. Tanggung Jawab \\
& 3. Standar Kerja \\
4. Upah \\
5. Kejelasan Organisasi \\
6. Semangat Tim \\
1. Niat Keluar \\
2. Mencari Pekerjaan Lain \\
3. Perasaan Bosan \\
4. Membandingkan Pekerjaan
\end{tabular}

Data yang digunakan dalam penelitian ini adalah data primer dan sekunder. Data primer merupakan sumber data yang langsung memberikan data kepada pengumpul data (Sugiyono 2014, 193). Teknik yang dipergunakan untuk pengumpulan data primer dilakukan dengan instrumen berupa kuesioner kepada responden di Divisi Keuangan PT. Mayora Indah Tbk Kantor Pusat Jakarta.

\section{HASIL PENELITIAN}

Tabel 4 Karakteristik

\begin{tabular}{lll}
\hline Karakteristik & Frekuensi & Persentase \\
\hline Jenis Kelamin & & \\
Laki laki & 31 & 34,8 \\
Perempuan & 58 & 65,2 \\
$\quad$ Total & 89 & 100 \\
Usia & & \\
21-30 Tahun & 28 & 31,5 \\
31-40 Tahun & 33 & 37,1 \\
41-50 Tahun & 20 & 22,5 \\
$\quad>51$ Tahun & 8 & 9 \\
Total & 89 & 100 \\
Pendidikan Terakhir & & \\
D3 & 12 & 13,5 \\
S1 & 62 & 69,7
\end{tabular}


S2

Total

Masa Kerja

1-5 Tahun

6-10 Tahun

11-15 Tahun

16-20 Tahun

$>21$ Tahun

Total
15

89

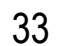

30

15

7

4
16,9

100

37,1

33,7

16,9

7,9

4,5

100

Sumber: output SPSS

Pada pertanyaan jenis kelamin, jumlah responden berjenis kelamin perempuan lebih sedikit dari jumlah responden berjenis kelamin laki laki. Total jumlah responden wanita sebanyak 58 orang atau $65,2 \%$ dan jumlah responden pria sebanyak 31 orang atau $34,8 \%$.

Usia responden terbanyak terdapat pada rentang $31-40$ tahun yaitu sebanyak 33 orang atau $37,1 \%$, kemudian responden dengan usia $21-30$ tahun yaitu sebanyak 28 orang atau $31,5 \%$, lalu usia $41-50$ tahun yaitu sebanyak 20 orang atau $22,5 \%$, kemudian usia $>51$ tahun sebanyak 8 orang atau $9 \%$.

Tingkat pendidikan terbanyak terdapat pada S1 yaitu sebanyak 62 orang atau $69,7 \%$, kemudian tingkat pendidikan pada S2 yaitu sebanyak 15 orang atau $16,9 \%$, dan tingkat pendidikan pada S2 yaitu sebanyak 15 orang atau $16,9 \%$,

Pada karakteristik masa kerja responden, paling banyak terletak pada rentang 1-5 tahun yaitu sebanyak 33 orang atau $37,1 \%$. Kemudian, pada rentang lama bekerja 6 tahun 10 tahun yaitu sebanyak 30 orang atau $33,7 \%$. Pada rentang 11 - 15 tahun sebanyak 15 orang atau $16,9 \%$. Pada rentang $16-20$ tahun yaitu sebanyak 7 orang atau $7,9 \%$ dan pada lama kerja $>21$ tahun yaitu sebanyak 4 orang atau $4,5 \%$.

Tabel 5 Uji Validitas

\begin{tabular}{lllll}
\hline Variabel & Item Pertanyaan & r Hitung & r Tabel & Hasil \\
\hline Stres Kerja & SK (1) & 0,783 & 0,208 & Valid \\
& SK (2) & 0,662 & 0,208 & Valid \\
& SK (3) & 0,691 & 0,208 & Valid \\
& SK (4) & 0,758 & 0,208 & Valid \\
Kepuasan Kerja & SK (5) & 0,743 & 0,208 & Valid \\
& KK (1) & 0,649 & 0,208 & Valid \\
& KK (2) & 0,702 & 0,208 & Valid \\
& KK (3) & 0,735 & 0,208 & Valid \\
& KK (4) & 0,656 & 0,208 & Valid \\
& KK (5) & 0,701 & 0,208 & Valid \\
& KK (6) & 0,722 & 0,208 & Valid \\
& IO (1) & 0,750 & 0,208 & Valid \\
& IO (2) & 0,678 & 0,208 & Valid \\
& IO (3) & 0,617 & 0,208 & Valid
\end{tabular}




$\begin{array}{lrrr}\text { IO (4) } & 0,777 & 0,208 & \text { Valid } \\ \text { IO (5) } & 0,670 & 0,208 & \text { Valid } \\ \text { IO (6) } & 0,638 & 0,208 & \text { Valid }\end{array}$

\begin{tabular}{ccccc} 
Turnover Intention & TI (1) & 0,733 & 0,208 & Valid \\
TI (2) & & 0,670 & 0,208 & Valid \\
TI (3) & & 0,681 & 0,208 & Valid \\
& $\mathrm{TI}(4)$ & 0,687 & 0,208 & Valid \\
\hline
\end{tabular}

Sumber :Output SPSS

Berdasarkan tabel diatas dapat diketahui bahwa semua variable independen yaitu Stres Kerja, Kepuasan Kerja, dan Iklim Organisasi serta variabel dependen yaitu Turnover Intention mempunyai $r$ hitung positif dan $r$ hitung $>r$ tabel. Sehingga dapat disimpulkan bahwa semua variabel dalam penelitian ini valid yang artinya tiap instrumen dapat digunakan untuk mengukur apa yang seharusnya diukur.

Tabel 6 Hasil Uji Reliabilitas

\begin{tabular}{|c|c|c|c|}
\hline Variabel & Jumlah Pertanyaan & Cronbach's Alpha & Hasil \\
\hline $\mathrm{X} 1$ & 5 & 0,787 & Reliabe \\
\hline X2 & 6 & 0,774 & Reliabe \\
\hline X3 & 6 & 0,773 & Reliabe \\
\hline Y & 4 & 0,774 & Reliabe \\
\hline
\end{tabular}

Berdasarkan tabel diatas, dapat diketahui bahwa semua variabel independen yaitu Stres Kerja (X1), Kepuasan Kerja (X2), dan Iklim Organisasi $(X 3)$ serta variabel dependen yaitu
Turnover Intention ( $Y$ ) mempunyai nilai Cronbach's Alpha $>0.60$, yang berarti instrumen dapat menghasilkan jawaban yang konsisten dari waktu ke waktu

Tabel 7 Uji Goodness of Fit Model

\begin{tabular}{lll}
\hline Model & F & Sig \\
\cline { 2 - 2 } 1 & 63,860 & 0,000
\end{tabular}

Sumber: : Output SPS 
Berdasarkan tabel 7 , dapat dilihat bahwa nilai sig sebesar 0,000 yang berarti $0,000<0,05$, maka dapat disimpulkan bahwa model fit digunakan dalam penelitian. Menunjukan bahwa, nilai $F$ hitung $>F$ tabel $(63,860>2,71)$ dapat disimpulkan bahwa model fit digunakan dalam penelitian.

Tabel 8 Hasil Uji Hipotesis

\begin{tabular}{llrl}
\hline & $\begin{array}{l}\text { Unstandardized Coefficients } \\
\text { B }\end{array}$ & T & Sig. \\
Model & & & \\
\hline (Constant) & 63.860 & 19.779 & .000 \\
TOTAL_X1 & -.281 & -2.552 & .012 \\
TOTAL_X2 & .089 & .808 & .422 \\
TOTAL_X3 & -.345 & -3.250 & .002 \\
\hline
\end{tabular}

Sumber: Output SPSS

Nilai sig pada variabel stres kerja sebesar 0,012 dimana nilai tersebut $<0,05$, maka dapat disimpulkan $\mathrm{H}_{1}$ diterima yakni variabel stress kerja berpengaruh signifikan terhadap variabel turnover intention di Divisi Keuangan PT Mayora Indah Tbk Kantor Pusat Jakarta. Dan nilai $t$ hitung $<\mathrm{t}$ tabel $(-2,552<$ 1,9876), maka Ho ditolak, variabel independen berpengaruh signifikan terhadap variabel dependen.

Nilai sig pada variabel kepuasan kerja sebesar 0,422 dimana nilai tersebut $>0,05$, maka dapat disimpulkan $\mathrm{H}_{2}$ ditolak yakni variabel kepuasan kerja tidak berpengaruh signifikan terhadap variabel turnover intention di Divisi Keuangan PT Mayora Indah Tbk Kantor Pusat Jakarta. Dan nilai thitung $<\mathrm{t}$ tabel $(0,808$ $<1,9876)$, maka Ho ditolak, variabel independen tidak berpengaruh signifikan terhadap variabel dependen.

Nilai sig pada variabel iklim organisasi sebesar 0,002 dimana nilai tersebut $<0,05$, maka dapat disimpulkan $\mathrm{H}_{3}$ diterima yakni variabel iklim organisasi berpengaruh signifikan terhadap variabel turnover intention di Divisi Keuangan PT Mayora Indah Tbk Kantor Pusat Jakarta. Dan nilai $t$ hitung $<\mathrm{t}$ tabel $(-3,250<$ 1,9876), maka Ho diterima, variabel independen berpengaruh signifikan terhadap variabel dependen.

\section{PENUTUP}

Simpulan sebagai berikut: (i) Terdapat pengaruh signifikan antara Stres Kerja terhadap Turnover Intention di Divisi Keuangan PT Mayora Indah Tbk Kantor Pusat Jakarta. (ii) Tidak terdapat pengaruh signifikan antara Kepuasan Kerja terhadap Turnover Intention di Divisi Keuangan PT Mayora Indah Tbk Kantor Pusat Jakarta. (iii) Terdapat pengaruh signifikan antara Iklim Organisasi terhadap Turnover Intention di Divisi Keuangan PT Mayora Indah Tbk Kantor Pusat Jakarta.

Hubungan kerja, beban kerja, peran dalam organisasi merupakan faktor dari stres kerja yang dapat menimbulkan turnover intention. Kesesuaian pekerjaan, upah promosi, rekan kerja, lingkungan kerja tidak mempengaruhi kepuasan kerja, tidak berdampak terhadap munculnya turnover intention. Kesesuaian dengan organisasi, kejelasan organisasi, standar kerja mempengaruhi pendapat individu terhadap turnover intention.

Adapun keterbatasan dalam penelitian ini adalah, sebagai berikut: (i) Penelitian ini hanya dilakukan di Divisi Keuangan PT Mayora Indah Tbk Kantor Pusat Jakarta karena keterbatasan perizinan. (ii) Jumlah sampel 
dalam penelitian ini hanya berjumlah 89 responden.

Adanya keterbatasan dalam penelitian ini sehingga peneliti menyarankan untuk: (i) Pada penelitian selanjutnya agar penelitian tidak hanya dilakukan pada Divisi Keuangan PT Mayora Indah Tbk Kantor Pusat Jakarta saja, tetapi pada divisi lainnya yang ada di PT Mayora Indah Tbk Kantor Pusat Jakarta. (ii) Pada penelitian selanjutnya untuk menggunakan sampel yang lebih besar. Sehingga, hasil penelitian dapat lebih menggeneralisasi populasi.

\section{REFERENCES:}

Arnanta, I Gede Putra. I Wayan Mudiartha Utama. 2017. Pengaruh Stres Kerja, Kepuasan Kerja Dan Iklim Organisasi Terhadap Turnover Intention Karyawan Cv. Dharma Siadja E-Jurnal Manajemen UnudVol. 6(6) Dessler, Gary. 2017. Human Resource Management. Pearson Education, Inc: New Jersey.

Handoko, T. Hani, 2008. Manajemen Personalia Sumber Daya Manusia, Edisi Kedua, Yogyakarta, Penerbit: BPFE. Panggabean, Mutiara Sibrani. 2004. Komitmen Organisasi Sebagai Mediator Variabel Bagi Pengaruh Kepuasan Kerja Terhadap Keinginan Untuk Pindah Kerja. Jurnal Bisnis dan Akuntansi. 6(1).

Robbins, Stephen P.2003. Perilaku Organisasi. Jakarta: Index.

Sugiyono. 2016. Metode Penelitian Bisnis. Bandung: Alfabeta.

Sukarman, Kamuli. 2012. Pengaruh Iklim Organisasi Terhadap Produktivitas Kerja Pegawai di Sekretariat Daerah Kota Gorontalo, Jurnal Inovasi. Universitas Negeri Gorontalo.

Sutrisno, Edy, 2012. Manajemen Sumber Daya Manusia. Jakarta: Pranada Media Group. 